\title{
EFFECTS OF EARTHQUAKES ON DAMS AND EMBANKMENTS
}

\author{
by \\ N. M. Newmark, D.Sc., Ph.D., M.S., M.I.C.E.*
}

I wish to thank the British Geotechnical Society for the opportunity of visiting London again and for the honour of appearing before you in the home of the Institution of Civil Engineers, of which I am so proud to be a member.

Several years ago I transmitted some preliminary notes on the topic of earthquake effects on dams to the late Karl Terzaghi, whose invaluable advice and suggestions regarding those notes were freely used in the preparation of this Paper. I wish also to acknowledge the comments and suggestions I have had from time to time concerning the subject from my colleague at the University of Illinois, Dr Ralph B. Peck; from my associate in several consulting assignments, Dr Laurits Bjerrum; and from my colleague for several months, while he was visiting the University of Illinois, Dr N. N. Ambraseys.

Finally, I should like to acknowledge the assistance on some of the calculations for this lecture that were made by two of my associates at the University of Illinois, Dr John W. Melin, and Mr Mohammad Amin.

\section{INTRODUCTION}

General description of earthquake motions

In an earthquake, the earth moves in a nearly random fashion in all directions, both horizontally and vertically. Measurements have been made of earthquake motions in a number of instances. In general, those measurements which are of greatest interest are the records of 'strong motion' earthquake accelerations, measured by the U.S. Coast and Geodetic Survey for a number of earthquakes in California in the past three decades. These accelerations, as a function of time, are available for motion in two horizontal directions as well as in the vertical direction, at a number of locations for several earthquakes. From the timerecord of the acceleration, the velocities and displacements can be computed by integration.

One of the most intense strong motion records available is that for the El Centro, California earthquake of $18 \mathrm{May}, 1940$. The record for the north-south component of acceleration of this earthquake is shown in Fig. 1, which also shows the values computed for velocity and displacement in the same direction. From the figure it can be observed that the maximum ground acceleration in the direction of this measurement is about $0.32 \mathrm{~g}$, the maximum ground velocity $13 \cdot 7 \mathrm{in} / \mathrm{sec}$, and the maximum ground displacement $8 \cdot 3 \mathrm{in}$.

The general nature of earthquake motions is indicated by this figure. It can be noted that the highest intensity peaks of acceleration have a relatively short period or a relatively high frequency; the most important peaks in the velocity, however, have a longer period which corresponds to a lower frequency; and the important peaks in the ground displacement have a much longer period still. For the ground conditions at El Centro the length of single loops of the highest intensities, in the various records, have durations of the order of the following : for acceleration, about 0.1 to $0.5 \mathrm{sec}$; for velocity, about 0.3 to $2 \mathrm{sec}$; and for displacement

* Professor of Civil Engineering, University of Illinois, Urbana, Illinois. 
about 1 to 4 sec. In other types of soil, the relative durations may differ, with softer soils in general showing lower magnitudes of acceleration, but longer durations and much larger displacements, than in Fig. 1.

It must be remembered that the El Centro earthquake is not the largest earthquake which has been experienced, even in California. It happened only to yield the most intense record at a point where a strong motion accelerograph was located.

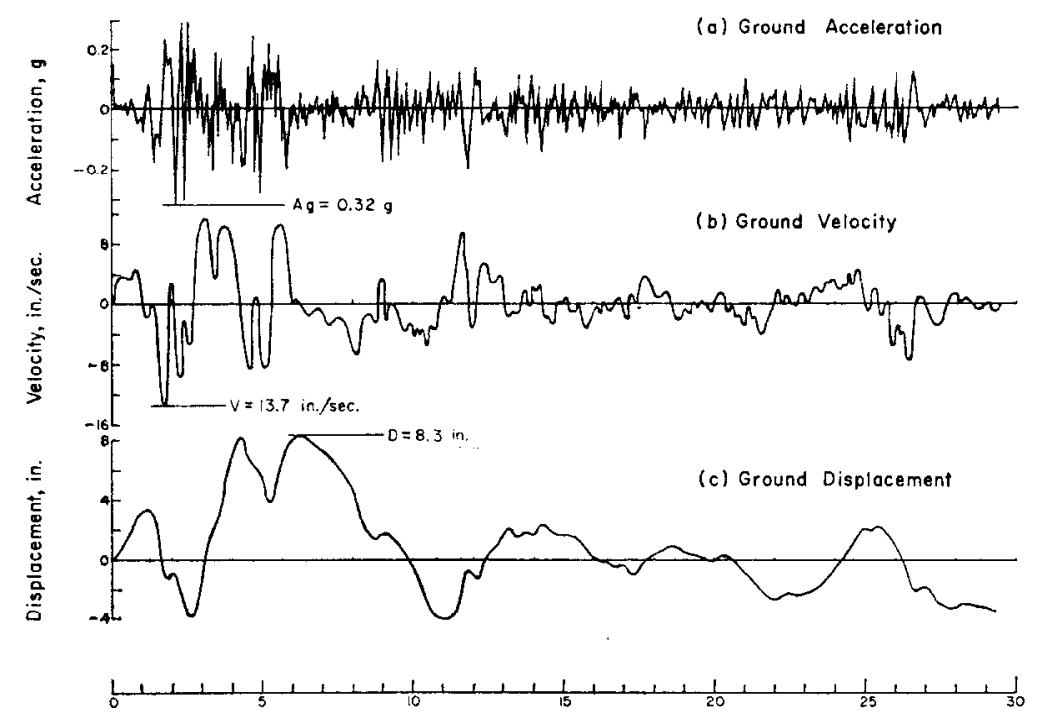

Fig. 1. El Centro, California, earthquake of 18 May, 1940, N-S component

\section{Significant factors of earthquake motion}

In considering the effect of an earthquake on a structure such as an earth or rock-fill dam, it is necessary to consider all of the aspects of the motion. In other words, the peak acceleration may not be significant in determining the response of the dam. The effects of the velocities and of the ground displacement, and of the differential displacement of the ground leading to fissures in the ground surface, may be of equal or of even greater importance. It will be shown later that the most important measure of the intensity of an earthquake is the maximum ground velocity reached at any time during the earthquake.

Records of the same general nature as those in Fig. 1 have been obtained for other earthquakes. Some major differences exist in the records, which show distinctive situations: in some cases an earthquake may correspond only to one short series of major pulses, with essentially only one major loop of displacement; and in other cases it may show an almost periodic displacement response for a large portion of time. The El Centro record is typical of a nearly periodic response of moderately low intensity combined with one very large displacement peak.

The durations of large motion in earthquakes vary from less than 10 seconds to as long as several minutes. The total duration and the total number of 'spikes' or peaks of velocity, and the reversals of velocity, are of importance in determining the response of a structure such as an earth or rock-fill dam, or embankment. 
In the studies made for this Paper, earthquakes have been considered patterned after those for which records are available in California, but which differ in some respects in terms of the significant frequencies of the various kinds of motion, and in the total duration of motion or number of spikes.

One of the most important special conditions existing at some sites is a relatively soft sedimental deposit of fairly great depth and wide extent. When such a soil deposit is set in to motion at its contact with the bed rock, there is a tendency for the resultant motions of the soil to reflect the natural frequency of the bowl of soil. This has the effect of increasing the magnitude of surface displacements and velocities, but it also causes the resultant motion to be more periodic in character, with many loops of successive displacement or velocity nearly in resonance, that is, having nearly the same period and with successive positive and negative peaks. A structure built on such material and hence subjected to such a motion will generally have a larger response than it would have if it were subjected to the motions of the bed rock.

\section{Intensities of maximum motion for major earthquakes}

Although earthquakes in many parts of the world may be less intense than the maximum recorded earthquake in California, in regions in which major seismic activity must be expected one should consider the probability of even larger motions. In any location, it is desirable to design for the maximum probable earthquake, that is, an earthquake that has a reasonable probability of occurring within the lifetime of the structure, with a sufficiently large factor of safety to preclude the necessity for major repairs. One should also consider an extreme carthquake, of about the maximum intensity that might be expected at the site, and for which some damage might be permissible, but collapse or failure should be prevented. Estimates of the maximurn probable earthquake that might occur once in a hundred years in California, and an extreme earthquake with only a relatively small chance of occurrence, are given in Table 1, for comparison with the maximum recorded earthquake in California. It is not considered likely that the extreme earthquake indicated in Table 1 would be exceeded anywhere in the world. The parameters indicated in Table 1 describing the intensity of possible earthquakes, are intended to apply to the general motions of the soil or rock away from the regions where the major fault motions occur. Although even at such fault motions, the accelerations and velocities are not likely to exceed the values tabulated, the displacements might be considerably greater, and the relative displacement at a fault may be of such a magnitude that it would cause damage or serious difficulty in a structure or a dam at the fault.

Table 1

Probable intensities of maximum motion for major earthquakes

\begin{tabular}{|c|c|c|c|c|}
\hline Condition & $\begin{array}{c}\text { Maximum } \\
\text { acceleration } \\
g\end{array}$ & $\begin{array}{l}\text { Maximum } \\
\text { velocity: } \\
\text { in } / \mathrm{sec}\end{array}$ & $\begin{array}{c}\text { Maximum } \\
\text { displacement: } \\
\text { in. }\end{array}$ & $\begin{array}{c}\text { Duration } \\
\text { of } \\
\text { major motion: } \\
\text { sec. }\end{array}$ \\
\hline $\begin{array}{l}\text { 1. Maximum recorded } \mathrm{EQ} \text {. in } \\
\text { California } \\
\text { 2. Maximum probable } \mathrm{EQ} \text {. in } \\
\text { California - }-\overline{-} \\
\text { 3. Extreme values considered }\end{array}$ & 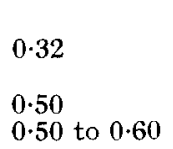 & $\begin{array}{l}24 \text { to } 30 \\
30 \text { to } 36\end{array}$ & $\begin{array}{l}12 \\
24 \\
36 \text { to } 48\end{array}$ & $\begin{array}{r}90 \text { to } 120 \\
120 \text { to } 240\end{array}$ \\
\hline
\end{tabular}

Note: Lower values of motions apply to rock, in general. 


\section{OBSERVED EFFECTS OF EARTHQUAKES}

Ambraseys (1962) ${ }^{1}$ points out that no major earth dam has been damaged by an earthquake during the last 25 years. However, he also points out that this argument can not be used as a proof for the adequacy of modern design methods, since no major dam built after the late thirties has been subjected to a severe earthquake. There have been a number of dams that have been damaged, or even destroyed, in earthquakes (Ambraseys, 1960, 1962). Moreover, it is generally true that in all compacted dam-construction materials, and in many natural soil strata, the dynamic shearing resistance is about the same as the static shearing resistance, or slightly greater, and the usual factor of safety is sufficiently large to prevent catastrophic motions. However, at some localities, natural soil strata are encountered which can lose part or almost all of their shearing resistance under shock conditions, either because of increased hydrostatic pressure or owing to loss in shearing strength from even slight remoulding. Under such conditions, major failures can occur, and have occurred, in embankments or under the foundations of dams which otherwise would not have suffered difficulties.

In the recent Anchorage earthquake, large

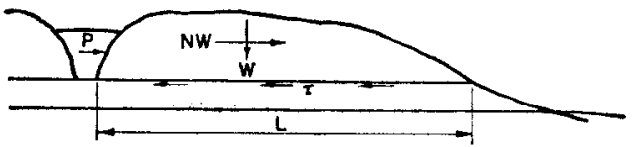

Fig. 2. Sliding of block in Anchorage (after Wilson) motions and catastrophic failures occurred in natural embankments which slid major distances on sensitive clay strata or on loose, low relative density sand layers. A typical example of the type of failure which occurred is shown in Fig. 2, taken from Shannon and Wilson (1964). The entire block of material of the order of $1000 \mathrm{ft}$ in length and 60 to $100 \mathrm{ft}$ in height, moved bodily tens of feet in an earthquake the maximum acceleration of which has been variously estimated as about $0 \cdot 15$ to $0 \cdot 18 \mathrm{~g}$.

Motions along a sliding surface may occur in a dam, under certain conditions, and a succession of slides of limited displacement on the upstrean and downstream faces of a dam are indicated schematically in Fig. 3, taken from Ambraseys (1958). The successive motions coming from the several shocks in different directions produce slides along different surfaces, with the net results shown at the bottom of the figure. The major settlement at the crest and the pattern of the deformations are similar to those which have been observed in several older dams which may not have been designed to have adequate earthquake resistance.

Tests of models of earth or rock-fill dams have been made by Davis and his associates at Berkeley (Davis et al., 1960; Clough and Pirtz, 1958), by Seed and his associates, also at Berkeley (Seed and Clough, 1963; Seed and Goodman, 1964), and by Bustamante (1964) at the University of Mexico. In granular material the patterns of slip are similar to those shown in Fig. 4. The outline marked 1 shows the original
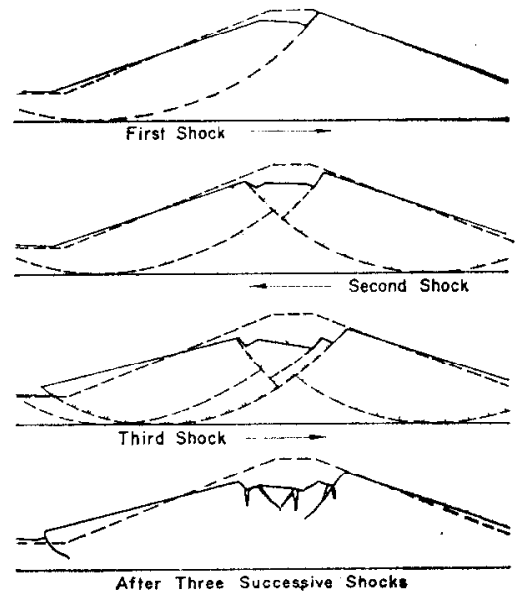

Fig. 3. Major deformation pattern (after Ambraseys) slope, that marked 2 shows the deformation after a relatively small shock, and the outline marked 3 shows the deformation after major motions have occurred. Similar motions have been observed when the base of the model was tipped, to simulate a constant acceleration field.

1 The references are given on p. 158 . 
Fig. 4. Patterns of glip in granular embankment

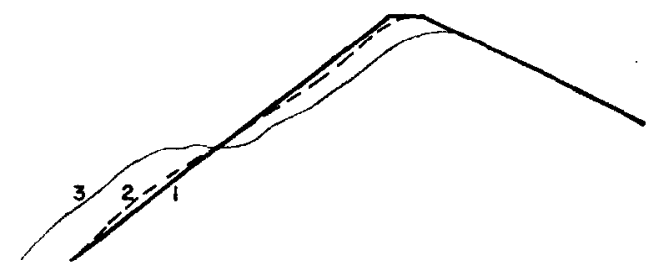

\section{General concepts of behaviour}

The types of motion of earth or rock-fill dams, or of an embankment, subjected to an earthquake can be considered to be of the following forms:

(a) motion of a block or wedge or slice of the upstream or the downstream slope, generally out and downhill, as indicated in Fig. 5, arcs ' $a$ ' or ' $b$ ';

(b) motion of the dam as a whole block, as in Fig. 5, line 'c';

(c) relative motions in either the dam or the foundation, of such a nature as to cause fissures to open, generally vertical, caused either by relative shearing motions or tensile strains in the earth crust, corresponding to differential movements arising from the wave characteristics of the surface motion of the earth, or from stresses arising when parts of

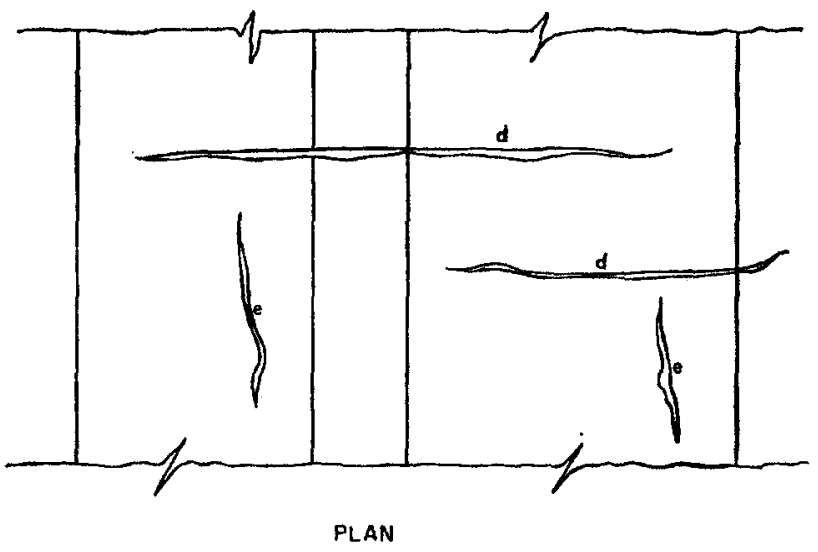
the mass of the dam and foundation are accelerated in one direction and other parts in other directions. This type of effect is illustrated in Fig. 5, by the fissures marked ' $d$ ' and ' $\mathrm{e}$ '.

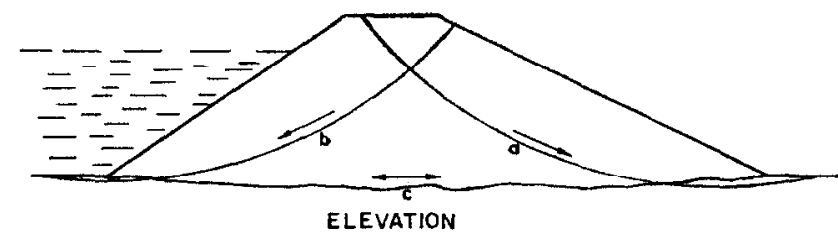

Fig. 5. Possible motions and deformations of an earth dam in an earthquake

Fig. 6. Comparison of two types of gross-motions

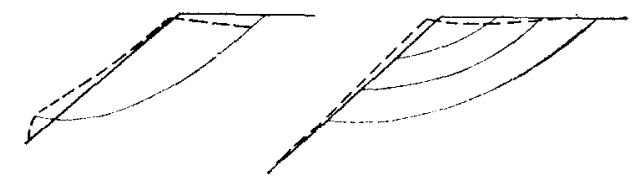

(o) Block Movement

(b) Gerieral Deformation 
The characters of the motions in different types of materials are somewhat different. In general, for non-cohesive materials, and for cohesive materials where a well-defined plane of weakness can develop, the motion occurs along arcs or planes, and is similar to that assumed in the usual static analysis of stability of an embankment, as indicated in Fig. 6(a). However, in highly cohesive materials, the motion is more nearly general and elastic or nearly elastic in character, and a well defined sliding surface may not be formed. This is illustrated in Fig. 6(b). Where movements such as those in Fig. 6(a) occur, a relatively simple analysis can be used to compute the magnitude of dynamic motions produced by earthquake or other shocks. However, where motions such as those in Fig. 6(b) occur, the situation is much more complex, and the analysis cannot be made so readily or so accurately. For this case, the methods described herein can only be used as a crude approximation. In general, we shall devote our further attention in detail to situations of the type illustrated in Fig. 6(a).

\section{Resistance to sliding motion}

The resistance to earthquake shock motion of a block of soil or rock that slides on a surface is a function of the shearing resistance of the material under the conditions applicable in the earthquake. Although the magnitude of the resistance depends on the amount of displacement, the displacement necessary to mobilize the average 'yielding' resistance, normally considered in a stability analysis, is not large. For the purpose of simplifying the calculations the resistance which we shall use is measured by (and in fact equal and opposite to) that steady force acting at the centre of gravity of the sliding mass, in the direction in which the force can have its lowest value, which will just overcome the stabilizing forces and will barely keep the mass moving, after it has started to move, or after several pulsations (or reversals) of motion have occurred.

It is convenient to state this resistance in terms of a coefficient $N$ multiplied by the weight of the sliding mass. Then the quantity $N g$, where $g$ is the acceleration of gravity, corresponds to that steady acceleration, acting in the proper direction, which would just overcome the resistance to sliding of the element, in the direction indicated, as defined above.

The resistance to sliding downhill, as on lines ' $a$ ' or ' $b$ ' of Fig. 5, is much lower than the resistance to sliding uphill on the same lines. The uphill resistance, without serious error in the calculations, may be taken as infinitely large. On the other hand, the type of motion characterized in line ' $c$ ' of Fig. 5 may have nearly the same resistance in either direction of relative motion of the mass compared with its foundation. This resistance may change as a function of displacement, and with reversal of displacement, but it is not generally greatly affected by the direction of motion other than in these ways.

We are not limited in the argument which follows by the use of a constant or steady-state value of $N$. We can consider the quantity $n$ to be a coefficient, multiplied by the weight of the sliding material, which is used as a measure of the resistance to sliding, and which can be a function of the amount of deformation, or of time, or of any other parameters which it is desirable to consider. It is convenient to use the single parameter $n$ as a measure of resistance, and to compare it with a single parameter $a$, as a measure of the acceleration driving the element. In other words, the quantity $n W$ is a measure of the resistance as a generalized force, and the quantity $a W$, where the transient ground acceleration is ag, is a measure of the disturbing force as a generalized force, which varies with time. For further simplicity, we may use $n=N$, the steady-state resistance ; and $a=A$, as a measure of the maximum ground acceleration, in developing approximate relationships.

\section{Dynamic properties of soil and rock}

In the determination of the value of sliding resistance, the dynamic properties of the material must be considered. This involves also the dynamic effects on the pore-water pres- 
sure, and the effects of the motion or shearing strain itself on the volume change and the pore pressure change. In general, it is the undrained shearing resistance that is of importance. For highly permeable materials, the drained shearing resistance may be appropriate. Because of the fact that our primary concern is with the resistance of the soil or rock and its strength under dynamic conditions, although the dynamic resistance is used in a sort of static analysis, we shall refer to the resistance as the 'pseudostatic' resistance. In other words, the calculation of stability which leads to the determination of the steady-state sliding resistance $N$ is made for properties of the material that are related to the dynamic situation.

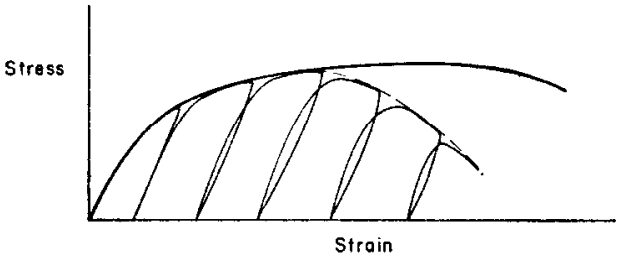

Fig. 7. Stress-strain relations for pulsating loads

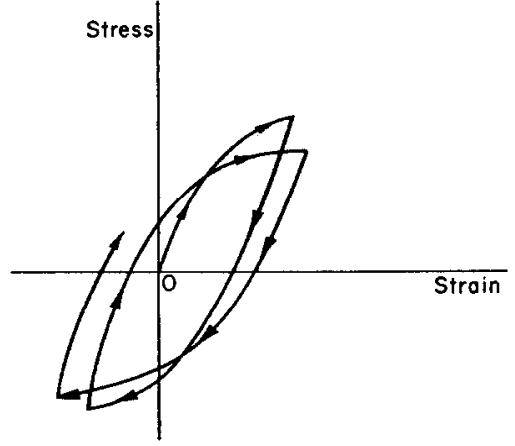

Fig. 8. Stress-strain relations for reversed loading

\section{Effect of pulsation or reversal of stress}

Because of the vibratory characler of earthquake shock motions, the direction of stresses and of deformations may reverse, or at least pulsate with relatively rapid fluctuations. In Fig. 7 is shown the relation between stress and strain for a load applied and released successively. So long as the strains are relatively small, for many soils the bounding curve to the pulsating stress-strain relation is the same as for a single application of stress. However, for some soils after a certain strain has been reached the stress may drop from the original virgin curve, as indicated by the dashed line on the right-hand side of the figure. The situation shown, with a diminishing resistance beyond the maximum, is not untypical of many sensitive soils. Where the stress is reversed, or where motions can take place in both directions, the reduction may be even greater, and the change in shape of the stress-strain relationship is very marked, possibly even more than is indicated in Fig. 8. Under these conditions a change in the resistance function $N$, with number of reversals or with time, is necessary if one is to account properly for the behaviour of the embankment.

\section{DYNAMIC RESPONSE THEORY}

The dynamic response of a deformable body can be computed by the direct application of Newton's laws of motion. However, in many cases this application is extremely tedious or involved. Some basic concepts and principles are available to permit a relatively simple summary of the responses to earthquake motions to be developed. These are described in some detail by Blume et al. (1961).

The Inaximum responses of a simple system such as that shown in Fig. 9, consisting of a single mass connected by an elastic spring to a movable base, are best described by the socalled 'response spectrum', which is a plot against frequency of one of several measures of the 
stress or deformation in the system. One of the most convenient ways of indicating the response for a variety of conditions is the tripartite logarithmic plot indicated in Fig. 10. The frequency $f$ of the mass-spring system is the abscissa. For a particular motion of the base, the maximum strain in the spring or relative displacement of the mass with reference to the base $D_{f}$, is plotted along the axis sloping up to the left. A quantity from which the maximum energy absorbed in this system may be readily computed, the pseudo-velocity $V_{\mathbf{f}}$ is plotted as the ordinate, vertically, and the maximum acceleration of the mass $A_{\S}$ is plotted along the axis sloping up to the right. For damping other than zero, the quantity that is plotted is not exactly equal to the acceleration but is the 'pseudo-acceleration'. The relations among the pseudo-velocity, the pseudo-acceleration, and the relative displacement, are indicated in Fig. 10. The spectrum shown in Fig. 10 is plotted against frequency rather than against period, as are those in Blume et al. (1961).

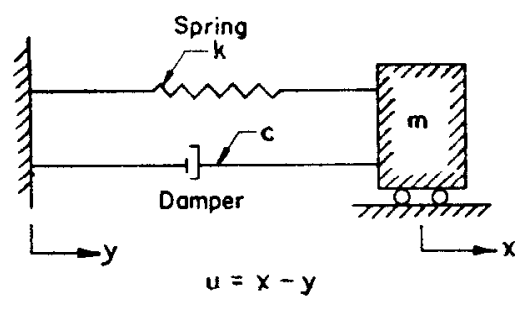

Fig. 9. System considered

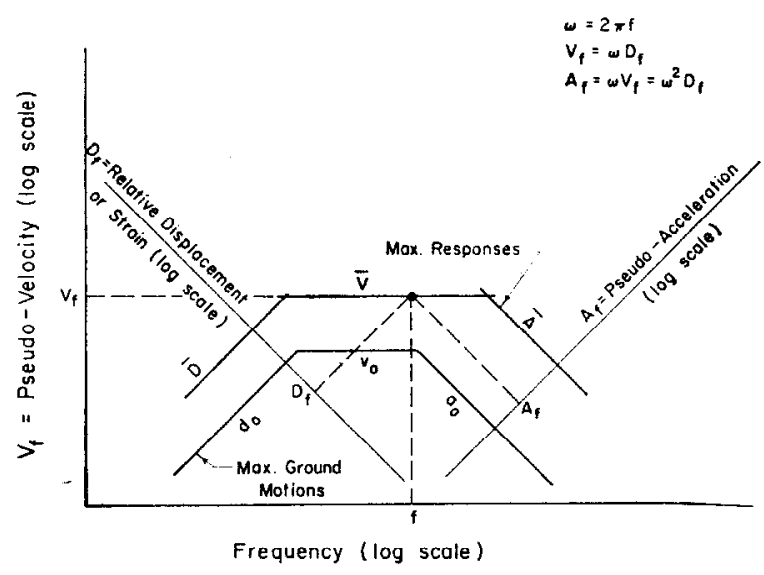

Fig. 10. Tripartite logarithmic response spectrum plot

For a base motion corresponding to the El Centro earthquake described in Fig. 1, the response spectra for several different values of the damping factor $\beta$, the proportion of critical damping for the system, are shown in Fig. 11.

The general characteristics of the response spectrum, as summarized from a great many studies of different input motions, are indicated in Fig. 10, where the quantities representing the maximum ground displacement $d_{0}$ the maximum ground velocity $v_{0}$, and the maximum ground acceleration $a_{0}$, are indicated schematically in the lower part of the figurc by straight lines. Then the response spectrum has the shape shown roughly by the upper series of three straight lines parallel to the lines just described, fairing in at the high and low frequency ends to the ground motion lines. The bounds to the response spectrum for displacement $\bar{D}$, pseudo-velocity, $\bar{V}$, and pseudo-acceleration, $\bar{A}$, are for moderate amounts of damping, of the order of 5 to $10 \%$, given by the relations

$$
\bar{D}=d_{0}, \bar{V}=1 \cdot 5 v_{0}, \bar{A}=2 a_{0}
$$

\section{Multi-degrec-of-freedom system}

The simplicity inherent in the description of the response of a single-degree-of-freedom system is not possible in describing the multi-degree-of-freedom system. A typical multi- 


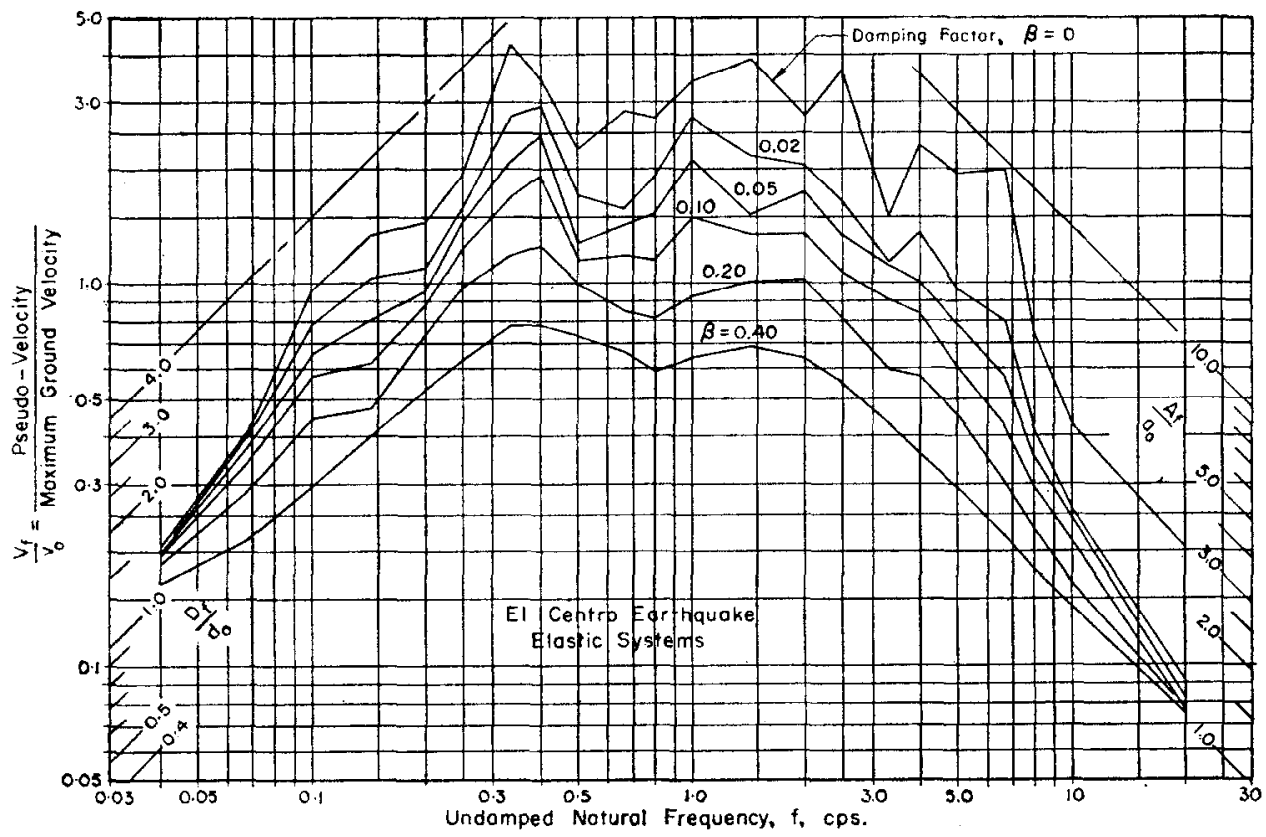

Fig. 11. Deformation spectra for elastic systems subjected to the El Centro qualre

degree-of-freedom system having the characteristics of a so-called 'shear beam' is shown in Fig. 12. A shear beam is a system made up of masses which can move horizontally with respect to one another. This is not untypical of the type of motion that occurs in a dam or embankment. Sketches of the modes of vibration of a typical shear beam are also shown in Fig. 12. Each of these modes has a frequency, with the fundamental mode having the lowest frequency, the second mode the next higher frequency, etc.

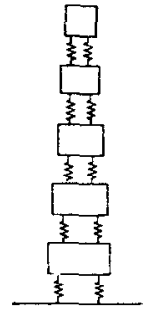

(a)

Mulfi-Degree-ofFreadom System

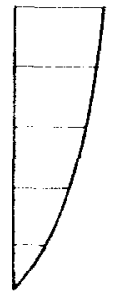

(b)

Fundomentol Mode

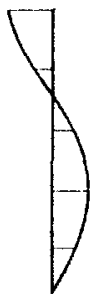

(c) Mode

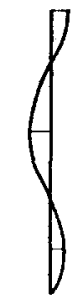

(d)

Third Mode

Fig. 12. Modes of vibration of shear beam

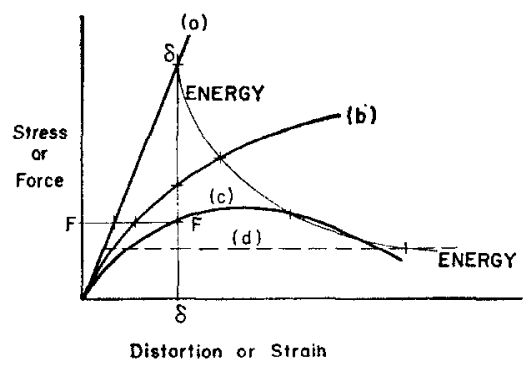

Fig. 13. Comparison of strains for equal displacement, energy, or force

The maximum strains or distortions in the springs, or the maximum stresses at any elevation, in a multi-degree-of-freedom system, can be stated in terms of the corresponding 
quantities for a set of single-degree-of-freedom systems corresponding to each of the modes of vibration. For a particular system, a plot similar to that in Fig. 10 can be drawn, as a function of the fundamental frequency.

\section{Inelastic relations between stress and strain}

The spectra indicated previously in Figs 10 and 11, for an elastic system, correspond to elastic behaviour, which is represented by the upper inclined straight line (a) in Fig. 13. There are also shown in Fig. 13 several inelastic relations between stress and strain, or between force and deformation. For an inelastic relation between stress and strain, corresponding to one of the curved lines such as (b) or (c) in Fig. 13, the spectrum as described previously cannot be used directly. Curve (b) corresponds to a strain hardening situation, and curve (c) to an unstable one. An elasto-plastic resistance is indicated by the dashed line (d), in Fig. 13.

Spectrum bounds for the distortion or strain can be derived from Fig. 10, as indicated by the schematic plot in Fig. 14. Here three different regimes are considered. At the left, for a frequency $f$, the inelastic spectrum bound $\bar{D}_{1}$ is the same as $\bar{D}$. At the right, the inelastic spectrum gives the displacement bound $\bar{A}_{1}$ corresponding to the same force as the elastic spectrum bound $\bar{A}$. Where we have an elasto-plastic resistance, the bound $\bar{A}_{1}$ may be infinitely far above $\bar{A}$.

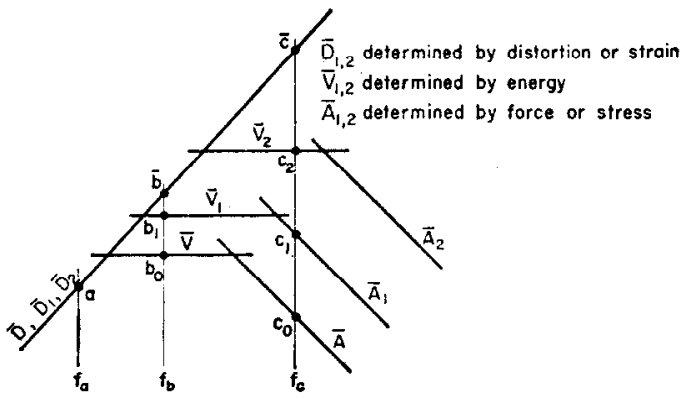

Fig. 14. Response spectrum displacement limits

In the intermediate range of frequencies, the spectrum bound $\bar{V}_{1}$ corresponds to the same total energy or area under the stress-strain curve as $\bar{V}$. These three conditions are illustrated in Fig. 13 by the lines marked FF at a constant force level, which intersects three of the curves but not the elasto-plastic curve; the line marked $\delta \delta$ which intersects all of the curves at the same displacement, and the line marked 'energy' which intersects all of the curves at such a point that the area up to that displacement is the same. In Fig. 14 two different levels of inelastic displacement are considered, corresponding to $\bar{V}_{1}$ and $\bar{V}_{2}$, or $\bar{A}_{1}$ and $\bar{A}_{2}$.

Results of a number of studies, still under way, indicate that in general the displacement for an inclastic system is bounded by the least of the following three quantities:

(1) a displacement corresponding to the same force as for the elastic spectrum bound $\bar{A}$;

(2) a displacement corresponding to the same energy as for the elastic spectrum bound $\bar{V}$;

(3) a displacement corresponding to the elastic spectrum bound $\bar{D}$. In other words, one can compute the displacement of the inelastic system by taking the smallest of the displacements that correspond to force, energy or maximum ground displacement, as indicated in Fig. 14. 
For very large amounts of plastic deformation, the acceleration bound for the inelastic spectrum lies so high that the energy bound is the only one of importance other than the displacement bound. Consequently, for large anounts of plastic deformation, it is appropriate to consider the preservation of energy, and to neglect the preservation of force, provided the stipulation is made that the displacement does not exceed the maximum ground displacement. Actually the displacement bound that should be considered is the maximum elastic spectrum displacement which may be slightly greater than the maximum ground displacement.

The methods described heuristically in the foregoing can be used for the analysis of systems in which the resistance varies with displacement. However, when the resistance is essentially rigidplastic, corresponding to no displacement until the yield point is reached, after which the displacement may have any value, the analysis is particularly simple. In the remainder of the analytical discussion herein, this is the type of resistance that is considered. We shall simplify the cases of motion to that of a rigid block of weight $W$, supported on a base which moves as a function of time. We are concerned with the motion $u$ of the block relative to the base. This model will be used for all of the cases of sliding that we have defined for a dam or embankment.

The three important

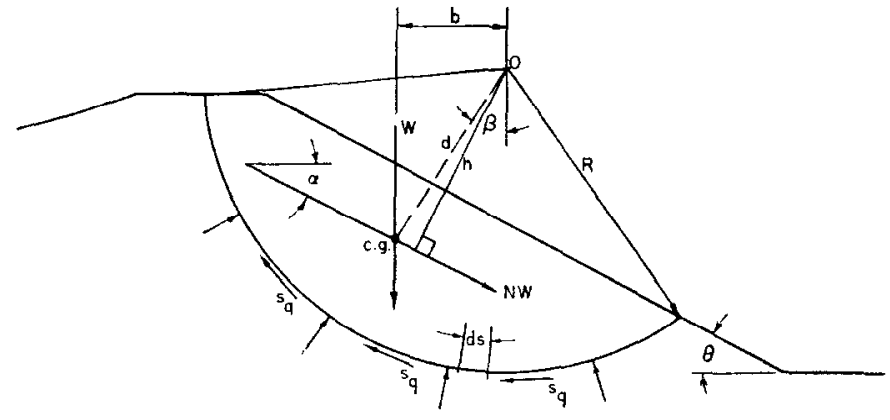

(a) Circulor Sliding Surface

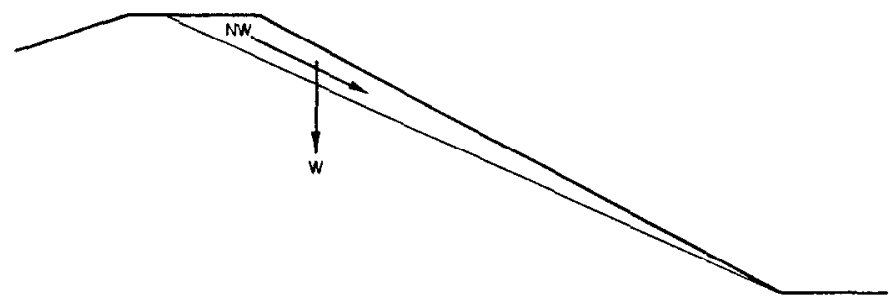

(b) Plane Sliding Surface

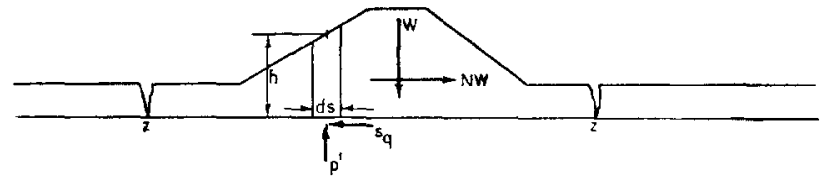

(c) Block Sliding

Fig. 15. Forces acting on a sliding element cases of sliding for a dam, on a circular sliding surface, on a plane sliding surface, or block sliding horizontally, are shown in Fig. 15. Of course, one might consider even more complex sliding surfaces if one can make the appropriate analysis for the resistance. For a general non-circular sliding surface the distortions within the sliding mass must be taken into account in arriving at the value of $N$ for the entire mass.

\section{Measures of dynamic resistance to sliding}

In order that a dam or embankment have any dynamic resistance to sliding in an earthquake, it must have a margin of safety against static failure. Values of the static factor of 
safety against sliding are determined by conventional analysis with no consideration of horizontal or inclined accelerations. Values of the dynamic factor of safety against sliding may be determined in a similar manner, but one must use in such an analysis the appropriate properties of the materials, which may involve considerably reduced shearing strengths owing to the dynamic effects on the pore pressures.

The method of analysis described here is a simplified approach permitting a rapid estimate to be made of the order of magnitude of the displacement or deformation in an earthquake.

\section{Circular cylindrical sliding surface}

Consider the sliding element of the dam shown in Fig. 15(a), where a circular arc of radius $R$ defines the sliding surface. The weight of the element $W$ has a lever arm $b$ about the centre of rotation $\mathrm{O}$. Consider a force $N W$ which corresponds to a constant acceleration $N$ times that of gravity, acting along the line shown making an angle $\alpha$ with the horizontal, which may be different from the angle $\theta$ of the surface slope of the element. For constant values of acceleration less than $\mathrm{Ng}$, no sliding occurs, but for greater values, sliding of the element will take place. For any arbitrary acceleration $N^{\prime} g$, we may define a dynamic factor of safety $\overline{F S^{\prime}}$, which becomes unity if $N^{\prime}=N$.

Now, when $N^{\prime}$ is taken as zero, the dynamic factor of safety, $\overline{F S^{\prime}}$ for this definition becomes equal to $\overline{F S}$, defined as the ratio of moment of the resisting forces on the sliding surface to the disturbing moment $W b$. This dynamic factor of safety is defined differently from the usual static factor of safety. Drawdown seepage forces, etc. should be taken into account, also, in defining the factor of safety.

The shearing stresses $\tau$ for static conditions are to some extent indeterminate, but their total or their average value can be detcrmincd from the relation between the disturbing moment $W b$ and the restoring moment $R \sum \tau d s$, when $N^{\prime}=0$ :

$$
W b=R \sum \tau d s .
$$

The moment of the resisting forces on the arc is $R \sum s_{\mathrm{q}} d s$. Hence the dynamic factor of safety is:

$$
\overline{F S}=R \sum s_{\mathrm{q}} d s / R \sum \tau d s=\sum s_{\mathrm{q}} d s / \sum \tau d s .
$$

An approximate value of $N$ which will just cause sliding is obtained by equating disturbing and resisting moments as follows:

$$
W b+N W h=R \sum s_{q} d s .
$$

Therefore, by subtracting equation (2) from equation (3), one obtains:

$$
N W h=R \sum s_{\mathrm{q}} d s-R \sum \tau d s .
$$

On dividing this equation by equation (2), and multiplying through by $b / h$, one obtains the result:

$$
N=\frac{b}{h}\left(\frac{\sum s_{\mathrm{q}} d s}{\sum \tau d s}-1\right)
$$

which can be written:

$$
N=\frac{b}{h}\left(\frac{\bar{s}_{\mathrm{q}}}{\bar{\tau}}-1\right) \quad \cdot \quad \cdot \quad \cdot \quad \cdot \quad . \quad \cdot \quad \cdot \quad \cdot \quad .
$$

if $\bar{s}_{\mathrm{q}}$ and $\bar{\tau}$ are considered as average values. This expression is valid for any case such as steady seepage or after rapid drawdown, but the value of $\bar{\tau}$ and $\vec{s}_{q}$ have to be determined separately for each case. Equation (4) can also be written as:

$$
N=(\overline{F S}-1) \frac{b}{h}
$$


Since the maximum value of $h$ for a given sliding surface occurs when $h$ equals $d$, the distance from $\mathrm{O}$ to the c.g. of the element, the minimum value of $N$ occurs for a slope perpendicular to $d$, and one finds for this:

$$
N=(\overline{F S}-1) b / d=(\overline{F S}-1) \sin \beta
$$

where $\beta$ is the angle between $d$ and the vertical, and $\overline{F S}=\bar{s}_{\mathrm{q}} / \bar{\tau}$.

For $N$ horizontal, the result would be :

$$
N=\overline{(F S}-1) \tan \beta .
$$

In the calculations, $N$ is taken as inclined rather than horizontal, in order to be conservative, and also because the earth moves vertically as well as horizontally in an earthquake.

For soils which have nearly the same static and dynamic shear resistance, equation (5) may be approximated as:

$$
N=(F S-1) \sin \beta
$$

in which $F S$ is the conventional static safety factor. This equation will hold good for freedraining materials and can also be used for dilatant soils in which only small or negative pore pressures will be developed.

When $N^{\prime}$ is different from zero, the same type of derivation leads to the relation:

$$
R \sum s_{\mathrm{q}} d s=\overline{F S^{\prime}}\left(W b+N^{\prime} W h\right) \quad . \quad . \quad . \quad . \quad . \quad \text {. }
$$

By equating equation (9) with (3), one obtains

$$
N=N^{\prime}\left(\overline{F S^{\prime}}\right)+\overline{\left(F S^{\prime}-1\right) b / h}
$$

which reduces to equation (5) when $N^{\prime}=0$ and $\overline{F S^{\prime}}=\overline{F S}$. Note, however, that equation (10) is valid even if $\overline{F S^{\prime}}$ is less than unity.

Because we are concerned with the minimum value of $N$ for all of the possible sliding surfaces, and because the minimum value does not necessarily occur for the sliding surface for which $\overline{F S}$ has a minimum value, use of equation (10), involving a trial value of $N^{\prime}$, will lead to more accurate results than use of equations (4) and (5) in which no assumed value of accelerating force is included in the basic computation. The most accurate results are obtained when $\overline{F S^{\prime}}$ is nearly equal to unity. The poorest results are obtained from the static factor of safety computed for the case of zero lateral force.

For completeness, the relations corresponding to (6) and (7) are given, for the case in which $N^{\prime}$ is different from zero: for $N$ perpendicular to $d$,

for $N$ horizontal,

$$
N=N^{\prime}\left(\overline{F S^{\prime}}\right)+\left(\overline{F S^{\prime}}-1\right) \sin \beta \quad \text {. . . . . . }
$$

$$
N=N^{\prime}\left(\overline{F S^{\prime}}\right)+\left(\overline{F S^{\prime}}-1\right) \tan \beta .
$$

\section{Block sliding}

For block sliding of the entire dam along a surface such as z-z in Fig. 15(c), between fissures or embankment surfaces, the relationships to be used involve summation of forces rather than summation of moments. For the static condition of equilibrium it can be assumed without significant error that the average static shear stress along the horizontal surface is zero and the only disturbing force is thus the effect of the horizontal constant acceleration. The maximum shear strength which can be mobilized for earthquake conditions is the undrained shear strength $s_{\mathbf{q}}$. 
Since the sum of the disturbing forces $N W$ per unit of width of dam must equal the sum of the shearing resistances per unit of width,

$$
N W=\sum s_{\mathrm{q}} d s
$$

where $d s$ is the length of the element on which the resistances act. Hence $N$ is the ratio of the total horizontal resistance to the weight of the dam.

The effective overburden pressure $p^{\prime}$ is equal to the weight of the material above minus the pore pressure; hence

$$
p^{\prime}=\gamma h-u_{\mathrm{p}} \quad \cdot \quad \cdot \quad \cdot \quad \cdot \quad \cdot \quad \cdot \quad \cdot
$$

where $\gamma$ is the bulk density of the soil, $h$ the height of the element, and $u_{\mathrm{p}}$ the pore pressure.

However,

$$
W=\sum \gamma h d s
$$

In general the undrained shear strength is a function of the effective overburden pressure. For the special case of a normally consolidated soil the ratio of $s_{\mathrm{q}}$ to $p^{\prime}$ is a constant.

From equations (13) and (14), for a normally consolidated soil, one can determine $N$ as follows:

$$
\begin{aligned}
N & =\frac{1}{W} \sum s_{\mathrm{q}} d s=\frac{1}{W} \sum \frac{s_{\mathrm{q}}}{p^{\prime}} p^{\prime} d s \\
& =\frac{1}{W}\left(\frac{s_{\mathrm{q}}}{p^{\prime}}\right) \sum p^{\prime} d s \\
& =\frac{s_{\mathrm{q}}}{p^{\prime}} \frac{\sum \gamma h d s-\sum u_{\mathrm{p}} d s}{\sum \gamma h d s} \\
& =\frac{s_{\mathrm{q}}}{p^{\prime}}\left(1-\frac{\sum u_{\mathrm{p}} d s}{\sum \gamma h d s}\right) \quad . \quad . . . . . .
\end{aligned}
$$

This equation can be written as

where

$$
\begin{aligned}
& N=\frac{s_{\mathrm{q}}}{p^{\prime}}\left(1-r_{\mathrm{u}}\right) \\
& r_{\mathrm{u}}=\frac{\sum u_{\mathrm{p}} d s}{\sum \gamma h d s} .
\end{aligned}
$$

The quantity $\boldsymbol{r}_{\mathrm{u}}$ is in general not a constant and has to be determined in each case as an average value. It should be taken at a conservative value to provide for pore pressure increase in an earthquake.

\section{Plane sliding surface}

For cohesionless and free-draining materials, with a plane sliding surface, as in Fig. 15(b), it is found that the most dangerous sliding plane is the upper slope, making an angle $\theta$ with the horizontal. Under these conditions, for a material with an angle of internal friction $\phi$ when sliding is taking place, the value of factor of safety against sliding is

$$
\overrightarrow{F S}=\frac{\tan \phi}{\tan \theta}
$$

It can be determined under these conditions that the minimum value of $N$ is

$$
N=(\overline{F S}-1) \sin \theta . \quad \cdot \quad \cdot \quad \cdot \quad \cdot \quad \cdot \quad \cdot \quad \cdot
$$

Sliding of a rigid-plastic mass

A simple derivation for a rigid-plastic resistance is developed to give a quick estimate of the magnitude of the motions to be expected in a sliding wedge of rock or earth in a dam, 
when it is subjected to the influence of dynamic forces from an earthquake. The calculation is based on the assumptions that the whole moving mass moves as a single rigid body with resistance mobilized along the sliding surface.

Consider the rigid body having a weight $W$, and a mass $M$, shown in Fig. 16, having a motion $x$. The motion of the ground on which the mass rests is designated by $y(t)$, where $y$ is a function of time $t$. The relative motion of the mass, compared with the ground, is designated by $u$, where

$$
u=x-y . \quad \text {. . . . . . . . . . (21) }
$$

The resistance to motion is accounted for by a shearing resistance, which can be expressed as being proportional to the weight $W$, of magnitude $N W$. This corresponds to an acceleration of the ground of magnitude $\mathrm{Ng}$ that would cause the mass to move relative to the ground.

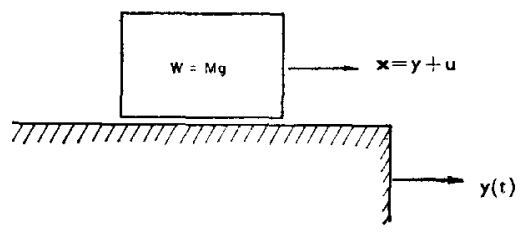

Fig. 16. Rigid block on a moving support

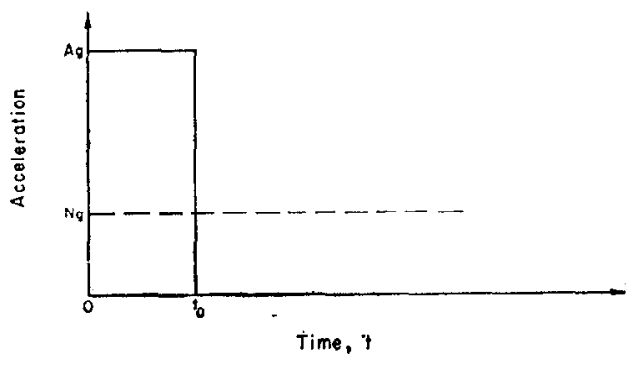

Fig. 17. Rectangular block acceleration pulse

In Fig. 17, the accelerating forces acting on the mass $M$ are shown. The acceleration considered is a single pulse of magnitude $A g$, lasting for a time interval $t_{0}$. It would be possible to consider a sinusoidal pulse, but this complicates the expressions unnecessarily. The resisting acceleration, $N g$, is shown by the dashed line in Fig. 17. The accelerating forcc lasts only for the short time interval indicated, but the decelerating force lasts until the direction of motion changes.

In Fig. 18, the velocities are shown as a function of time for both the accelerating force and the resisting force. The maximum velocity for the accelerating force has a magnitude $V$ given by the expression

$$
V=A g t_{0} \text {. }
$$

After the time $t_{0}$ is reached, the velocity due to the accelerating force remains constant. The velocity due to the resisting acceleration has the magnitude $N g t$. At a time $t_{\mathrm{m}}$, the two

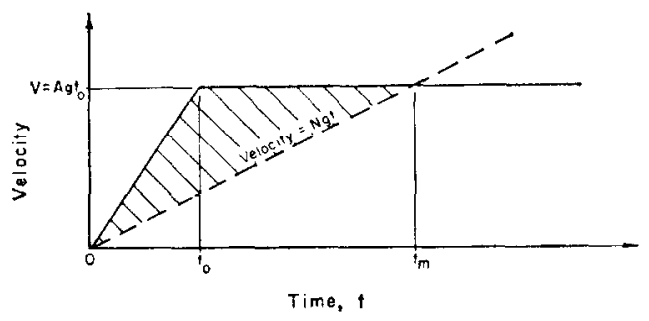

Fig. 18. Velocity response to rectangular block acceleration 
velocities are equal and the net velocity becomes zero, or the body comes to rest relative to the ground. The formulation for $t_{\mathrm{m}}$ is obtained by equating the velocity $V$ to the quantity $N g t$, giving as a result the expression

$$
t_{\mathrm{m}}=\frac{V}{N g} \quad \cdot \quad \cdot \quad \cdot \quad \cdot \quad \cdot \quad \cdot \quad \cdot \quad \cdot \quad .
$$

The maximum displacement of the mass relative to the ground $u_{\mathrm{m}}$ is obtained by computing the shaded triangular area in Fig. 18. The calculation is made as follows:

or

$$
\begin{aligned}
& u_{\mathrm{m}}=\frac{1}{2} V t_{\mathrm{m}}-\frac{1}{2} V t_{0} \\
& u_{\mathrm{m}}=\frac{1}{2} \frac{V^{2}}{N g}-\frac{1}{2} \frac{V^{2}}{A g} \\
& u_{\mathrm{m}}=\frac{V^{2}}{2 g N}\left(1-\frac{N}{A}\right)
\end{aligned}
$$

whence

The acceleration pulse shown in Fig. 17 corresponds to an infinite ground displacement. The actual situation corresponds to a number of pulses in random order, some positive and some negative. If we consider a second pulse, of a negative magnitude, to bring the velocity to zero even without the resisting force, it can be shown that the net displacement with the resistance generally cannot exceed that which would occur without resistance.

The result given in equation (23) generally overestimates the relative displacement for an earthquake because it does not take into account the pulses in opposite directions. However, it should give a reasonable order of magnitude for the relative displacement. It does indicate that the displacement is proportional to the square of the maximum ground velocity.

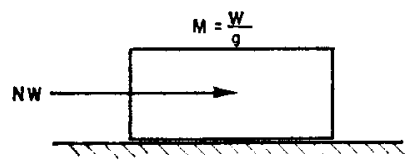

Fig. 19. Mass sliding under constant force

The result derived above is applicable also for a group of pulses when the resistance in either direction of possible motion is the same. For a situation in which the body has a resistance to motion greater in one direction than in another, one must take into account the cumulative effect of the displacements. A simple example where this must be considered would be found if Fig. 16 were rotated clockwise, as in Fig. 19, so that the body has a tendency to slide downhill. In this situation, ground motions in the direction of the downward slope tend to move the mass downhill, but ground motions in the upward direction along the slope leave the mass without relative additional motion except where these are extremely large in magnitude. One may consider that this case is applicable to the dam.

\section{Energy concepts}

Another interpretation of equation (23) may be useful. Consider the situation where the sliding mass of material acquires somehow a velocity $V$ relative to the ground or foundation. This velocity may be imparted by motion of the foundation and that part of the dam which presses against the sliding wedge, but in any event, it is the velocity of the mass, relative to the ground or foundation on which it slides, that is needed. This is not necessarily the same as the maximum ground velocity.

The kinetic energy of the moving mass, with this velocity, then is given by the relation $W V^{2} / 2 g$. The resistance to sliding is given by the quantity $N W$ and the energy absorbed in the sliding resistance is $N W$ times the displacement. It follows, therefore, that the displacement required to absorb the kinetic energy is given by the first term on the right of equation 
(23), namely, $V^{2} / 2 g N$. The solidus term takes into account to some extent the manner by which the mass acquires its velocity.

We may extend the energy concept to other types of force displacement relationships such as shown in Fig. 13 or even more complex relations. It is of particular interest to compute the relative displacement for an elasto-plastic resistance as compared with a purely elastic resistance. To do so one can compare the two types of resistance shown in Fig. 20 and note that areas 1 plus 2 plus 3 , for the elastic resistance energy, must be equal to areas 1 plus 2 plus 4 for the elasto-plastic resistance energy.

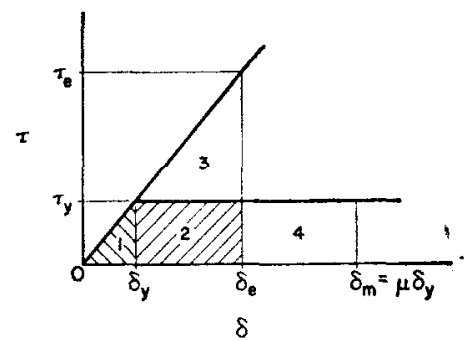

Fig. 20. Conventionalized elastic and elasto-plastic stress-strain diagrams

From this relation, taking note of the fact that

one derives the result

$$
\tau_{e} / \tau_{y}=\delta_{e} / \delta_{y}
$$

$$
\begin{aligned}
\frac{\delta_{\mathrm{y}}}{\delta_{\mathrm{e}}} & =\frac{1}{\sqrt{ }(2 \mu-1)} \\
\frac{\delta_{\mathrm{m}}}{\delta_{\mathrm{e}}} & =\frac{\mu}{\sqrt{ }(2 \mu-1)} .
\end{aligned}
$$

In these equations, as indicated in Fig. 20, $\mu$ is the ratio of the maximum total displacement to the elastic component of displacement. For purely elastic conditions, $\mu=1$.

For a rigid-plastic resistance, the energy absorbed at a maximum displacement $\delta_{m p}$ is $\delta_{m p} \tau_{y}$, whereas for the elasto-plastic resistance, the energy absorbed at a maximum displacement $\delta_{\mathrm{m}}$ is

$$
\delta_{\mathrm{m}} \tau_{\mathrm{y}}(1-1 / 2 \mu)
$$

Then, for the same energy the relative value of maximum displacement is:

$$
\delta_{m} / \delta_{m p}=1 /(1-1 / 2 \mu)
$$

The maximum value of this ratio is $2 \cdot 0$. For even moderate values of $\mu$, however, the ratio is close to unity.

\section{Number of effective shocks in an earthquake}

Since the sliding of either the upstream or downstream slopes in an earthquake can only occur downhill, if sliding occurs at all there will be a lowering of the crest of the dam caused by a cumulative slip on both slopes, always downhill. The net motions of either slope can be determined only after assumptions are made of: $(a)$ the input motions of the ground; (b) the effective number of spikes of accelerations similar to one of the single spikes considered in Fig. 17 and in the derivation of equation (23) ; and (c) the resistance of the sliding elements.

The effective number of pulses in an actual earthquake can be determined by an analysis of the response of simple systems to the earthquake motion. This has been done for four of the West Coast United States earthquakes for which strong motion records are available. These four are described in Table 2.

For convenience in interpreting the results the four earthquakes were normalized to a 
maximum acceleration of $0.5 \mathrm{~g}$ and a maximum ground velocity of $30 \mathrm{in} / \mathrm{sec}$, by modifying the acceleration and time scales appropriately. Normalized displacements are given in Table 2 for each of the earthquakes.

The analysis was made on the high-speed digital computer at the University of Illinois Digital Computer Laboratory for the normalized accelerograms for the earthquakes. The results are plotted in Fig. 21 for a symmetrical resistance function, in which the resistance is rigid-plastic but having the same value in each direction of motion. It appears from Fig. 21 that the results are bounded by the expression for energy $V^{2} / 2 g N$, and also by the maximum displacement $y_{0}$ of the ground. Where the value of $N$ approaches the maximum earthquake acceleration, there is a reduction in response from that given by the energy expression, as shown by the equation in the lower right-hand part of the figure, in which the correction factor derived in equation (23) appears to be applicable. Apparently this is important only beyond a value of $N / A$ greater than 0.5 .

Table 2

Earthquakes considered in analysis

\begin{tabular}{|c|c|c|c|c|c|}
\hline \multirow[t]{2}{*}{ Earthquake } & \multicolumn{4}{|c|}{ Maximum ground motions } & \multirow{2}{*}{$\begin{array}{l}\text { Normalized * } \\
\text { displacement : } \\
\text { in. }\end{array}$} \\
\hline & $\begin{array}{c}\text { Acceleration } \\
g\end{array}$ & $\begin{array}{l}\text { Velocity } \\
\text { in } / \mathrm{sec}\end{array}$ & $\begin{array}{l}\text { Displacement: } \\
\text { in. }\end{array}$ & $\begin{array}{c}\text { Duration: } \\
\text { sec. }\end{array}$ & \\
\hline $\begin{array}{l}\text { 1. Ferndale, } 21 \text { Dec., } \\
\text { 1954, N45E } \\
\text { 2. Eureka, } 21 \text { Dec., } \\
\text { 1954, S11W - } \\
\text { 3. Olympia, 13 April, } \\
\text { 1949, S40W - } \\
\text { 4. El Centro, } 18 \text { May, } \\
\text { 1940, N-S }\end{array}$ & $\begin{array}{l}0 \cdot 205 \\
0 \cdot 178\end{array}$ & $\begin{array}{r}10.5 \\
12.5 \\
8.28\end{array}$ & $\begin{array}{c}8 \cdot 26 \\
10 \cdot 0 \\
9 \cdot 29 \\
8 \cdot 28\end{array}$ & $\begin{array}{l}20 \\
26 \\
26\end{array}$ & $\begin{array}{l}27 \cdot 7 \\
51 \cdot 2 \\
20 \cdot 5 \\
25 \cdot 5\end{array}$ \\
\hline
\end{tabular}

* Normalized to give acceleration $=0.50 \mathrm{~g}$

and velocity $=30 \mathrm{in} / \mathrm{sec}$.

\section{Unsymmetrical resistance}

When the motion takes place with a different resistance in the two directions, corresponding to a mass sliding downhill, as in Fig. 19, the displacement is increased greatly. Although there is a smooth transition between the value given in Fig. 21 and the greatly increased value corresponding to completely unsymmetrical resistance, the results approach very rapidly those corresponding to an infinite resistance in one direction. The results of calculations for this case are summarized on Fig. 22. A conservative upper bound to the computed values of displacement is given by the relation

$$
\frac{V^{2}}{2 g N} \cdot \frac{A}{N} \quad \cdot \quad \cdot \quad \cdot \quad \cdot \quad \cdot \quad \cdot \quad \cdot \quad \cdot \quad \cdot \quad \cdot
$$

This appears to indicate that the effective number of pulses in the earthquakes considered is equal to the quantity $A / N$. If one multiplies equation (23) by $A / N$, one obtains a bound which is somewhat closer in the region where $N / A$ is larger than about 0.5 , but is not conservative for somewhat smaller values. For very low values of $N / A$, the number of effective pulses in the earthquake apparently is no greater than 6 for the earthquakes considered. This, however, may be considered a peculiarity of the particular earthquakes examined. It would be undoubtedly true that for earthquakes lasting for a longer time the number of effective pulses would be greater. Preliminary studies indicate a relative value for longer durations roughly proportional to the square root of the duration. 


\section{Comparisons with model tests}

The theoretical procedures described herein have been applied to tests of a model of a rockfill dam, described by Davis et al. (1960). The scale of the model was $1 / 300$ of the prototype. The dynamic tests of the model were made by striking a shaking table with a heavy pendulum. A rebound of the pendulum caused a second input at a lower acceleration. Hence, data could be obtained both for the initial strike and for the first rebound.

On the whole, the model tests indicated a fair agreement with the calculations, for comparable conditions. Within the accuracy of the records obtained in the tests, the measured motions were in fairly good agreement with the results computed by means of equation (23) and Fig. 21.

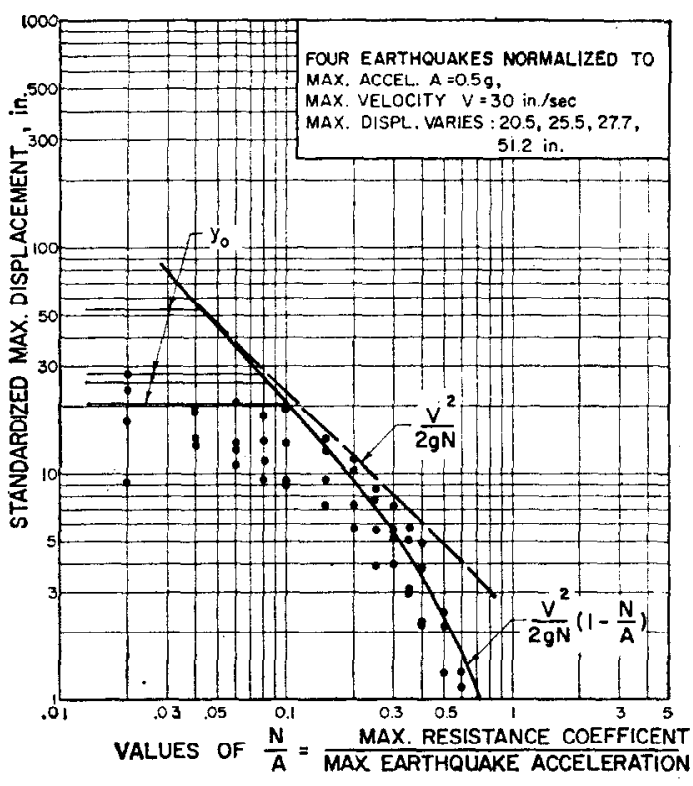

Fig. 21. Standardized displacement for normalized earthquakes (symmetrical resistance)

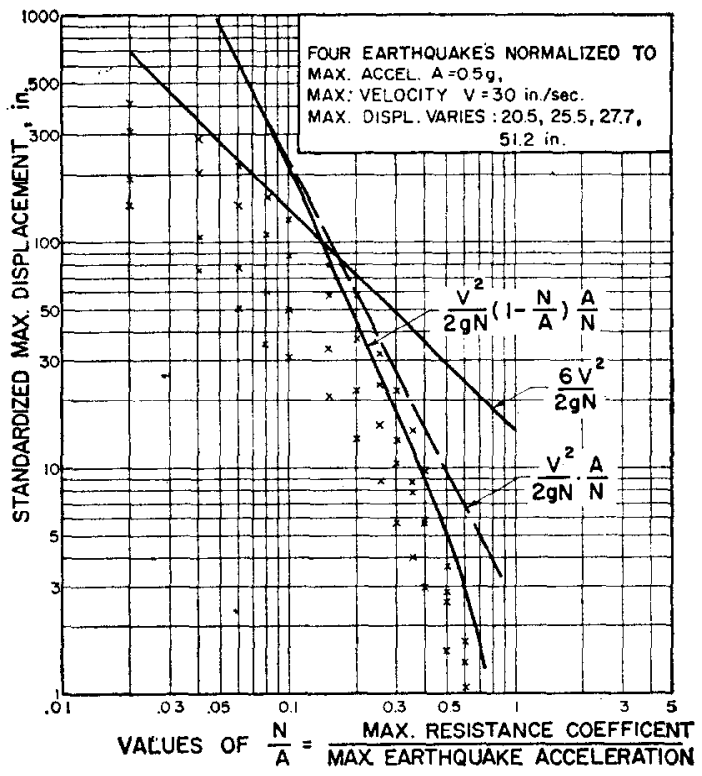

Fig. 22. Standardized displacement for normalized earthquakes (unsymmetrical resistance)

\section{Comments and conclusions}

For the maximum probable earthquake in California, which is a reasonable maximum earthquake for many other areas of the world, Fig. 22 may be used directly to obtain a measure of the maximum displacement for unsymmetrical sliding. If the maximum resistance coefficient is about $0 \cdot 16$, or about one-third the maximum earthquake acceleration, the net displacement will be about $1 \mathrm{ft}$. If the maximum resistance coefficient $N$ is about 0.20 times the maximum earthquake acceleration, or $N$ equals $0 \cdot 1$, the maximum displacement is about $5 \mathrm{ft}$. The maximum displacement increases rapidly as $N$ decreases. Values of $N$ in the range of $0 \cdot 1$ to $0 \cdot 15$ are not uncommon for earth dams designed for earthquake resistance. Of course, a design with a somewhat smaller value of $N$ would have a smaller displacement if the earthquake were less intense. For an earthquake with a maximum acceleration of $0.25 \mathrm{~g}$, and a maximum velocity of $15 \mathrm{in} / \mathrm{sec}$, the displacements computed would be one-fourth those quoted, if the value of the ratio of $N$ to $A$ were the same. In other words, for the same relative value of resistance coefficient, the displacement varies as the square of the ground velocity. This displacement lowers the crest of the dam. 
Another factor that must be considered in the design of a dam is overtopping caused by wave action. Such wave action can be initiated by slumping of the dam but it is more likely to be caused by slides from unstable natural areas in the reservoir. Slides of this sort caused failure of the Vaiont Reservoir in Italy; the dam itself did not fail structurally.

Faulting or sudden settlement may also cause wave action. Such a settlement that took place very rapidly at the dam itself caused the large waves at Hegben Lake (Anon, 1964).

Damage and serious danger may occur if an earth dam is in the neighbourhood of the fault where the fault may intersect the dam and cause a break or fissure through it. When an earth dam is founded on rock or a firm soil stratum, and is made of well compacted material, the danger in an earthquake may be minimal. However, if the dam is located above a stratum which can liquefy or lose its shearing strength an earthquake may cause a failure by spreading of the dam even though the dam itself may have an ample factor of safety with respect to failure in the material of the dam itself. In general, sites underlain by strata which may suffer a major reduction in shearing resistance should be considered unsuitable unless the sensitive strata can be removed.

Open cracks across the impervious section of an earth dam can form as a result of differential settlement of the base of the dam, or as a result of differential movements within the body of the dam, as well as a result of earthquakes. Transverse cracks may develop even in earthquake-free regions. Because an earthquake with even moderately large motions may introduce fissures and cracking which may lead to piping, provisions should be made to induce selfhealing of open cracks. Dr Terzaghi has suggested that such provisions might consist of establishing the impervious section of the dam, or core, between two layers of properly graded cohesionless material. These layers should be only moderately compacted, and in each layer the grain size should increase with increasing distance from the contact surface with the impervious core. A method of this sort was adopted by Terzaghi for Mission Dam.

In arriving at the design of a dam which is required to resist earthquake motions one may either adopt a procedure in which the static resistance of the dam is greater than the maximum earthquake acceleration likely to be encountered, or one can make the dam capable of resisting displacements corresponding to those computed by the methods described herein. The former approach gives a misleading sense of security because of the fact that there are small displacements that take place even when $N$ equals $A$ or exceeds it, owing to the fact that resisting forces are developed even by elastic displacements less than the yield point. Hence the motions can be of such a nature as to cause a reduction in shearing stress and a consequent amplified displacement.

It may be required, to avoid permanent displacements altogether, that the value of $N$ be well in excess of the maximum earthquake acceleration. This appears to be too uneconomical a procedure for general use.

For years engineers were convinced that foundations did not settle if they were adequately designed. The methods introduced by Terzaghi concentrated attention on methods by which the settlements could be determined and subsequent measurements indicated that almost all foundations settle. One might expect that the same situation applies to earth and rock-fill dams and embankments. When one concentrates attention only on the strengths and neglects the displacements or motions, one is not likely to realize that these motions will take place. It is desirable to try to keep them at a level such that they can cause no danger.

\section{REFERENCES}

Ambraseys, N. N., 1958. 'The seismic stability of earth dams.' Ph.D. dissertation, University of London. Ambraseys, N. N., 1960. 'On the seismic behaviour of earth dams.' Proc. 2 nd World Conf. on Earthquake Engng, Tokyo, vol. 1, p. 331 .

AMBRASEYS, N. N., 1962. 'The seismic stability analysis of earth dams.' Second Symposium on Earthquake. Engineering, University of Roorkee, Roorkee, India. 
Avon, 1964. 'The Hegben Lake, Montana, earthquake of August 17, 1959.' Geological Survey Professional Paper 435. U.S. Government Printing Office, Washington, D.C.

Blume, J. A., N. M. Newmark, and L. H. Corning, 1961. "Design of multi-storey reinforced concrete buildings for earthquake motions.' Portland Cement Association, Chicago.

Bustamante, J. I., 1964. 'Dynamic behaviour of non-cohesive embankment models.' Ph.D. dissertation, University of Illinois.

Clough, R. W. and D. Pirtz, 1958. 'Earthquake resistance of rock-fill dams.' Trans. Amer. Soc. civ. Engrs, 123 : $792-810$.

DAvis, R. E. and associates, 1960. 'Model study of stability of Portage Mountain Dam during earthquakes.' Berkeley, California, November 1960. (Report to International Power and Engineering Consultants Ltd, Vancouver, Canada.)

Seed, H. B. and R. W. Clough, 1963. 'Earthquake resistance of sloping core dams.' Proc. Amer. Soc. civ. Engrs, 89 (SM1) : 209-242.

Seed, H. B. and R. E. Goodman, 1964. 'Earthquake stability of slopes of cohesionless soils.' Proc. Amer. Soc. civ. Engrs, 90 (SM6) : 43-73.

Shannon and Wilson, Inc., 1964. Report on Anchorage area soil studies, Alaska, to U.S. Army Engineer District at Anchorage, Alaska, 28 August, 1964.

The Chairman invited Mr J. Guthrie Brown, President of the International. Commission on Large Dams, to propose the vote of thanks.

Mr J. GuThrIE Brown said that it gave him very great pleasure to be invited to propose the vote of thanks to the distinguished lecturer, Professor Newmark.

Professor Casagrande, Dr Cooling, M. Armand Mayer, and Professor Skempton-these were the names of the world-famed experts who had given the four previous Rankine Lectures.

He could imagine that Professor Newmark, seeing these distinguished names, and the scope of their lectures, must lave felt that even he had to give of his best to maintain the high standard of the Rankine Lectures.

Yet all present would surely agree that Professor Newmark's lecture took an honoured place as the Fifth Lecture. Music lovers mentioned Beethoven's Fifth as a landmark in the development of symphonies. Was it too much to claim the same for the Rankine Fifth this evening? Like Beethoven, Professor Newmark was a master of his profession.

Mr Brown had had the pleasure of meeting Professor Newmark a few years ago, when he and his colleague from Norway, Dr Lauritz Bjerrum, had advised Mr Brown's firm on possible earthquake effects for a proposed dam in Pakistan. He was, therefore, not a stranger to Professor Newmark's vast experience on the subject of earthquakes.

As a Scot from Glasgow, he was proud to be speaking at a lecture named after the distinguished Scot, William John Macquorn Rankine, born in 1820, and trained as an engineer. In the comparatively short life of 52 years, Rankine had carried out a fantastic amount of scientific study and research, which included submitting over 150 papers on a wide variety of subjects to the Royal Society.

Professor Skempton had said that in about the same time Professor Newmark had written the same number of papers. Looking at Professor Newmark and his absence of grey hairs suggested that he had at least another 100 up his sleeve.

One of the treasures in Mr Brown's technical library was a copy of Rankine's book 'Civil engineering', written in 1862 when he was Professor of Civil Engineering at Glasgow University. It was he who had advanced the transformation of civil engineering from the 'rule of thumb' methods to the science it had become, not least in his studies into the logical design of dams.

While, Mr Brown said, he must be honest and admit that he did not refer much to Rankine's book nowadays, he had looked it up to see if he had made any reference to the effect of earthquakes on structures. He had not mentioned this aspect at all, from which one could deduce that whatever were the afflictions that Glasgow and its citizens suffered from, earthquakes were not among them.

Speaking as President of the International Commission on Large Dams, he thought it probably true to say that engineers dealing with major dam design were now more concerned 
with the nature and stability of the foundations on which these mighty structures were supported than in the effect of earthquakes, unless they were built in a zone susceptible to earthquakes. Two dams in the U.S.S.R. at present under construction were $988 \mathrm{ft}$ high, so that the first $1000 \mathrm{ft}$ dam was obviously not far distant.

It was possible that the International Commission would decide to set up a new Committee this year to study the safety of foundations for large dams. Recent major dam disasters had mainly been associated with foundation failures, with the exception of that in Italy.

It was noticeable that the modern world tendency was to build embankment type dams, which greatly outnumbered other types of large dams being constructed. For example, since 1945 there had been built throughout the world about 4000 dams, and of these the embankment type amounted to $\mathbf{5 5} \%$, and the percentage was increasing steadily all the time. Professor Newmark's lecture on the effect of earthquakes on embankment dams was, therefore, all the more valuable for this reason.

Japan, with nearly 2000 large dams, second only to U.S.A. with $\mathbf{3 5 0 0}$ large dams, was a country with probably more earthquakes than any other, and yet had had relatively few failures. As had already been pointed out, there had been no important damage to a major dam during the past 25 years.

The subject of earthquakes and their effect on the design of dams had already been closely discussed at two recent International Congresses on large dams, Paris in 1955 and Edinburgh in 1964. He could well imagine this subject being raised again at another congress in the near future.

For two large concrete dams with which his firm was concerned in the Middle East-one arch and one buttress type-the model studies for design simulated seismic conditions up to and beyond that recorded at $\mathrm{El}$ Centro in 1940. The results obtained were most helpful in ensuring safer design. He thought that the value of model experiments which simulated earthquake conditions could not be overstressed in the case of large dams.

The Japanese, with up to 1000 minor earthquakes recorded each year, and a destructive earthquake every second year, had probably given more thought to the design of earthquake resistant structures than any other country. Their Building Standard Law revised during 1964, was intended to cater for earthquake conditions up to the El Centro magnitude, with regulations covering almost all types of structures from dams to tall buildings, towers, etc.

An example of their advanced design was in the case of the atomic power station at Tokai Mura, north of Tokyo. The reactor was designed generally on similar lines to the Hunterston Station in Scotland. It had required courage and confidence to design and build a large nuclear station safely to withstand the earthquake conditions which could occur in Japan.

Japanese engineers were prepared to design up to 40-storey buildings in Tokyo to resist earthquakes. In fact, the critical conditions nowadays in some cases of high structures was the effect of typhoons and not earthquakes.

In case a 40-storey earthquake-resistant structure was thought to be unique, he reminded the meeting that Professor Newmark had been consulted on the design for a 43 -storey office building in Mexico City which had successfully resisted a major earthquake in 1957.

He had, therefore, very much pleasure in moving a vote of thanks for this outstanding Rankine Lecture given by Professor Newmark, the contents of which, he was sure, would be referred to by engineers from all over the world for many years to come.

The vote of thanks was carried with acclamation. 